\title{
Persevering toward What? Investigating the Relationship between Ninth-grade Students' Achievement Goals and Perseverant Actions on an Algebraic Task
}

\author{
Joseph DiNapoli ${ }^{1 *}$ \\ ${ }^{1}$ Montclair State University, Montclair, NJ, USA \\ *CORRESPONDENCE: $₫$ dinapolij@montclair.edu

\begin{abstract}
Perseverance is vital for the process of learning mathematics with understanding. To do so, students must wrestle with obstacles and amend their problem-solving plan when necessary. I collected qualitative data to investigate the nature of perseverance for 11 ninth-grade algebra students working on a challenging task for which they affirmed interest. Employing analytical frameworks of achievement goal perceptions and subsequent perseverant actions, the findings perseverant actions are not always aligned with students' goals of meaning-making. Although students may report being motivated by building conceptual understanding, they may not fully grasp what it means to achieve such mastery goals. I provide suggestions for teachers to further encourage the development of more perseverant learners.
\end{abstract} \\ inform three distinct profiles of in-the-moment perseverance states. These profiles suggest that
}

Keywords: perseverance, achievement goals, algebraic task, problem-solving

\section{INTRODUCTION}

Current standards toward improving mathematics achievement de-emphasize memorization of problemsolving routines and instead encourage students to learn mathematics with understanding. In this sense, understanding means mental connections among mathematical facts, ideas, and procedures (Hiebert \& Carpenter, 1992). However, building mathematical understanding requires perseverance toward specific achievement goals during problem-solving (Middleton, Tallman, Hatfield, \& Davis, 2015). As such, expectations for student perseverance have been made explicit in standards for mathematical practice (CCSSMP, 2010). Yet, little research exists about the specific ways in which students can persevere. An important next step in understanding perseverance in problem-solving is to explore what it should (and should not) look like as students work toward accomplishing their problem-solving goals (Bass \& Ball, 2015; Warshauer, 2014).

\section{PERSEVERANCE AND LEARNING MATHEMATICS}

Perseverance has long been recognized as vital to the learning process because learners must experience and overcome in-the-moment struggles to achieve deep mathematical understandings. Here, the idea of struggle does not imply unneeded frustration with extreme challenges. Instead, struggle refers to the productive action of wrestling with key mathematical ideas that are within reach, but not yet well formed (Hiebert et al., 1996). Dewey (1910) described this process of productive struggle as requiring both time and

Article History: Received 14 January $2019 \bullet$ Revised 18 February $2019 \bullet$ Accepted 21 February 2019

(C) 2019 by the authors; licensee Modestum Ltd., UK. Open Access terms of the Creative Commons Attribution 4.0 International License (http://creativecommons.org/licenses/by/4.0/) apply. The license permits unrestricted use, distribution, and reproduction in any medium, on the condition that users give exact credit to the original author(s) and the source, provide a link to the Creative Commons license, and indicate if they made any changes. 
effort in the face of some problem-solving confusion: to think about the conceptual aspects of the problem, piece together ideas, try to make sense of them, and work out methods for resolving the dilemma. Festinger (1957) echoed this philosophy in his theory of cognitive dissonance, positing that some perplexity presents a rich opportunity to learn through restructuring one's mental connections among mathematical ideas. Moreover, Pólya (2014) described such struggle with key mathematical ideas is a natural part of doing mathematics: learning with understanding requires exploring different problem-solving strategies to help reveal and refine connections among ideas. In all, persevering to overcome struggles is logically related to learning mathematics with understanding. If mathematical understanding is mental connections among facts, ideas, and procedures, then struggling is a process that happens in-the-moment to re-form these connections when old connections are found to be inadequate to make sense of a new problem (Hiebert \& Grouws, 2007).

Although student perseverance has been well connected to learning mathematical concepts, the notion of what counts as perseverance is not so clear. Generally, people usually think about perseverance as stickingwith-it, or not giving up in the face of a challenge, to accomplish a particular achievement goal. However, this idea of perseverance can be interpreted in many different ways. In some cases, not giving up is couched as a productive disposition that paves the way for accomplishing long-term goals (see Bandura, 1997; Dweck, 2006; Duckworth et al., 2007; Linnenbrink \& Pintrich, 2003; Wrosch et al., 2003). Yet in other cases, not giving up is considered closer to the moment, as observable engagement during problem-solving to accomplish shortterm, in-the-moment goals (see Bandura \& Schunk, 1981; Gallagher \& De Lisi, 1994; Middleton, Tallman, Hatfield, \& Davis, 2015; Sansone, Wiebe, \& Morgan, 1999; Warshauer, 2014).

In this study, I adopt an in-the-moment conception of perseverance defined by Middleton and colleagues (2015) as "the continuance of effort, carried out in a thorough and diligent manner, towards some perceived goal while overcoming difficulties, obstacles, or discouragement along the way by amending one's plan of attack" (pp. 4-5). Perseverance describes the productive actions taken by a problem-solver in the face of a challenge as he or she struggles to make progress toward a goal, even after encountering a setback of some kind. Such perseverance is not easy for most students. Frustration is a common outcome while struggling with mathematical obstacles, and research has shown students can often disengage from exploratory efforts when a problem is not quickly and easily solved (Kapur, 2011; Schoenfeld \& Sloane, 2016). Thus, a student-centered investigation is warranted into the nature of perseverance toward particular problem-solving goals within a challenge mathematical task. By "challenging mathematical tasks" I mean tasks for which a solution pathway was not immediately apparent for the student.

\section{GOALS OF STUDY AND RESEARCH QUESTIONS}

My goal in this exploratory research was to learn more about the nature of ninth-grade algebra students' achievement goals and subsequent perseverance in the context of working on a challenging mathematical task for which they reported interest. In this qualitative study I observed and interviewed 11 ninth-grade algebra students before, during, and after their individual engagement with a challenging mathematics problem. I hoped to discern exactly how a student was persevering (or not) with the problem, as well as the goal he or she specifically hoped to achieve through these efforts. Influenced by prior conceptions of perseverance, I aimed to investigate research questions that will help me clarify what it means for an interested student to persevere in the moment toward particular goals and how educators can use this information to encourage perseverance, and consequentially, learning mathematics for understanding. My two research questions were: (a) How did ninth-grade algebra students describe their achievement goal(s) while engaging with a challenging mathematical task requiring perseverance for which they reported interest? (b) In what ways did ninth-grade algebra students persevere, if at all, with a challenging mathematical task requiring perseverance for which they reported interest?

\section{PERSEVERING WITH INTEREST, TOWARD GOALS, AND WITH ACTION}

During work on a challenging mathematical task, perseverance matters because students are likely to encounter obstacles. Much of the scholarship on perseverance, although relatively scarce, addresses how teachers can support students as they encounter such obstacles during problem-solving, such as by asking timely questions (see Freeburn \& Arbaugh, 2017; Kress, 2017) or by raising awareness about the productive outcomes of perseverance (see Kapur, 2010, 2011; Warshauer, 2014). Empirical questions remain, however, about students' own motivations for perseverance in problem-solving and how these motivations might relate to overcoming mathematical obstacles. To address student motivations and perseverance in problem-solving, 
I investigated (a) whether the student was interested in solving the task, (b) the perceived achievement goal toward which the student was working, and (c) the observed problem-solving actions the student took while working on the task. Combining these phenomena to describe one's work on a challenging mathematical task paints a comprehensive picture of how and why an individual persevered (or did not) in a particular situation.

\section{The Role of Interest}

One of the most predominant factors related to student perseverance is interest in the task at hand. Interest describes the cognitive and emotional state of an individual during engagement in particular situations aligned with the motivational disposition to continue and/or return to engagement over time (Renninger \& Bachrach, 2015). Situational interest can be framed as in-the-moment interest during problemsolving, and such interest can have positive impacts on continued student engagement with a task (Ames \& Archer, 1988; Duda \& Nicholls, 1992; Eccles \& Wigfield, 2002; Gottfried et al., 2007; Harackiewicz et al., 2008; Linnenbrink \& Pintrich, 2004; Middleton \& Spanias, 1999; Pintrich, 1989; Ryan \& Deci, 2000). When students are interested in solving a problem they are likely to wrestle with obstructive obstacles because of a personal investment in the situation. Such individuals can also be more likely to continue working on problems, even if they are challenging, because such engagement is deepening their personal interest level (Hidi \& Renninger, 2006). Use of self-regulatory strategies such as elaborative processing skills and monitoring and evaluating one's own progress can coincide with interest (Lepper, 1988; Zimmerman, 1990). These connections between situational interest, continued engagement, and self-regulation suggest ample effects on student perseverance.

\section{The Role of Achievement Goals}

When an individual is presented with a task to solve, their perseverance may be guided by a personal achievement goal. Although many things can influence a person's goal, including interest, achievement goal research has largely centered on the issue of competence. Elliot and McGregor (2001) argue that competence, and thus achievement goals, can be differentiated by two basic elements: how it is defined and how it is valenced. Competence can be defined based on an intrapersonal mastery standard or an interpersonal performance standard (Dweck, 1986; Dweck \& Elliott, 1983; Dweck \& Leggett, 1988; Elliot \& McGregor, 2001; Nicholls, 1984). Individuals conceptualizing their own competence as personal growth and building their understanding are said to have set a mastery goal for the task at hand. Conversely, individuals conceptualizing their own competence relative to the achievement of peers on the same task are said to have set a performance goal.

Another dimension of competence is valence. This means individuals may be motivated toward positive possibilities of competence and/or away from negative possibilities of incompetence (Ames, 1992, Butler, 1992; Dweck, 1986; Elliot, 1999, 2005; Nicholls, 1984; Urdan \& Mestas, 2006). In other words, the intrinsic attractiveness or averseness of a particular task situation can serve to inspire persons to approach success or avoid failure, respectively. Elliot (1999) illustrated this distinction within both mastery and performance goals by distinguishing between participants focusing on possibilities of both positive and negative outcomes. Therefore, incorporating a dimension of valence divides goals of mastery and performance into sub-goals of approach and avoidance. In this way, the achievement goal framework depicts four possible outcomes: mastery-approach goal, mastery-avoidance goal, performance-approach goal, or performance-avoidance goal. While working on a challenging task, an individual's achievement goal orientation is believed to shape whether or not they persevere and attempt to overcome encountered obstacles (Ames, 1992; Ames \& Archer, 1988; Blackwell, Trzesniewski, \& Dweck, 2007; Dweck, 1986, 2006; Elliot, 2005; Elliot \& McGregor, 2001; Furner \& Gonzalez-DeHass, 2011; Harackiewicz, Barron, Pintrich, Elliot, \& Thrash, 2002; Karabenick, 2003, 2004; Meece, Blumenfeld, \& Hoyle, 1988; Urdan \& Mestas, 2006). Operating from a mastery-approach perspective is generally associated most with a tendency to persevere because of the positive relationships with seeking self-improvement and self-reports of tendencies of meaningful effort (Elliot, 2005). A student acting in this state is likely to strive toward increasing their understanding through exploratory work, often guided by a growth mindset (Dweck, 2006). Goals of mastery-avoidance are also generally supportive of perseverance, though not to the degree of mastery-approach (Elliot \& McGregor, 2001). Mastery-avoidance orientations have shown positive relationships with self-regulation and effort, but also with self-reports of potentially debilitating emotions. A student acting in this state is seemingly motivated by the possibility of not learning and is presumably persevering to avoid misunderstandings. 
Performance goal orientations are less likely to support perseverance because of connections to competitiveness and ego (Elliot \& McGregor, 2001; Urdan \& Mestas, 2006). A student acting in this state is likely to focus on the outcome of the task and whether they were able to showcase their superior ability relative to their peers. A sense of fulfillment is directly connected to success in interpersonal performance, and often times one's ability is perceived as fixed (Dweck, 2006). Performance-approach goals can encourage perseverance, but only if an individual experiences success by these standards (Furner \& Gonzalez-DeHass, 2011). Without performing better than fellow classmates, a student in this state is susceptible to more quickly giving up in future in similar situations, which could lead to a shift toward performance-avoidance goals. In this way, perseverance guided by performance-approach goals is viewed as unstable. Performance-avoidance orientations seem to be the least supportive of student perseverance because of the positive relationships with self-reports of fear of failure and potentially debilitating emotions, and the negative relationship with selfreports of control strategies. A student acting in this state suggests protecting their ego at all costs by avoiding any challenges that risk their incompetence being exposed, that is, their ability level relative to their peers'. Students making this goal choice are seriously impeded when facing learning obstacles, often demonstrated through quick disengagement or no engagement at all.

\section{Perseverance as Action}

Although it is helpful to study the perceived achievement goals that drive one's perseverance, it is also important to define the specific actions that constitute perseverance in the moment with a challenging mathematical task. Problem-solving is a fruitful context in which to study perseverance because non-routine tasks provide obstacles standing in the way of learning something new (Stanic \& Kilpatrick, 1989). The CCSSMP (2010) makes explicit in-the-moment actions that exemplify perseverance, including planning an entry point to the task, considering analogous tasks, exploring different representations, monitoring and evaluating one's own progress, and changing course when necessary. Toward a perceived problem-solving goal, Middleton et al. (2015) conceptualize perseverance as the diligent continuance of effort while overcoming encountered setbacks by modifying one's particular problem-solving plan. Dolle, Gomes, Russel, and Byrk (2013) discuss perseverance as "productive persistence, defined as tenacity plus effective strategies" (p. 451) while working.

The specific actions of perseverance exist within the malleable stages of problem-solving. Polya (1971) describes a four-stage problem-solving model including (a) understanding the problem, (b) devising a plan, (c) carrying out the plan, and (d) reflecting on the effectiveness of the plan. The first two stages of the model suggest the importance of domain specific knowledge for perseverance because a student knowledge-base can propel designs of how to enter and explore the problem (Kantowski, 1977; Schoenfeld \& Herrman, 1982; Silver, 1979, 1985; Wilson, 1993). In this way, these stages are preparatory for student perseverance during problemsolving. As students recognize alignment between the problem at hand and resources in their knowledge-base, they are more likely to plan to use task-specific heuristics, in addition to more general heuristics, to help navigate specific decision-making moments during problem-solving with mathematical challenges (Wilson, 1993). Keying in on specific features of the problem to influence decision making is not a guarantee for success, but can be useful in facilitating a better understanding of the problem situation, supportive of developing a new plan of attack that was not obvious at the onset. However, successful problem-solvers employ problemsolving heuristics to persevere past obstacles to reach a point of sense-making such that they can refine their strategy when needed (Schoenfeld, 1989; Silver, 1985). Such exploratory actions can include drawing diagrams, guessing and checking, using logical reasoning, looking for patterns, making a table of values, etc. (see Schoenfeld, 1979). In the latter two stages of Polya's (1971) problem-solving model, students must apply and reflect upon their preparations in an uncertain mathematical situation where obstacles will certainly arise. Metacognition is of the utmost importance because problem-solvers must monitor, direct, and control their own cognitive processes to continue to make progress (Flavell, 1976; Schoenfeld, 1992). It is through these self-regulatory behaviors that students are able to persevere; i.e., explore their plans for solving a problem, notice progress or the lack thereof, and decide to change course if necessary.

Since perseverance is intended to be productive (toward learning mathematics for understanding), one way to interpret "thorough and diligent" (Middleton et al., 2015) effort and use of "effective strategies" (Dolle et al., 2013) is to deem the mathematical progress one has made due to the investment of effort on a particular task. When an individual is working on a task for which a solution pathway is not already known, they are constantly evaluating the efficacy of their effort. Such metacognition is crucial because it influences whether the individual will use certain control or self-regulatory strategies to change course if needed (Carver \& 
Scheier, 2001). When certain efforts are not helping an individual progress toward their goal, awareness of the flaws in their plan is important to motivate an individual to try something new. Evidence of such metacognition can vary, and Gresalfi and Barnes (2015) suggest how mathematical or consequential justification can inform why one might decide to change course while working on a challenging mathematical task. Compelling evidence of mathematical progress is achieving mathematical awareness through effort, that is, an individual uses the mathematical connections they have made (i.e., "this plan is not working because the slope of my function is incorrect") to justify their decision to change course. Less compelling evidence of mathematical progress is achieving consequential awareness through effort, that is, an individual uses consequences of a plan (i.e., "this plan is not working because I'm not getting the right answer") to justify a decision to change course.

Outside of considering the specific productive actions of a learner while working on a challenging task, many researchers operationalize the notion of sticking-with-it through a simple time-on-task measure (e.g., Bandura \& Schunk, 1981; Gallagher \& De Lisi, 1994; Vollmeyer \& Rheinberg, 2000), or through binary observations of choosing to continue with or stop working on a task (e.g., Ainley, Hidi, \& Berndorff, 2002; Ainley, Hillman, \& Hidi, 2002; Tulis \& Fulmer, 2013). Although related to perseverance, these measures more closely resemble persistence, conceptualized by Peterson and Seligman (2004) as stubborn effort while pursuing a short-term goal. Perseverance is different from persistence because it includes the flexibility of altering one's original plan if it is not successful, not just steadfast insistence. Nevertheless, persistence is generally believed to be beneficial for mathematics learning because it implies the learner values something about the task at hand and is willing to stay engaged in some way.

\section{Interest and Achievement Goals Driving Perseverance}

The purpose of this investigation was to learn more about the nature of students' perceived achievement goals and subsequent perseverance in the context of working on a challenging mathematical task for which they reported interest. During challenging work, a student's interest and personal goals for achievement can drive subsequent perseverance. Interest and goals have an interdependent relationship - interest level in a task can encourage different types of achievement goals, and different types of achievement goals for a task can trigger varying levels of interest. Each of these constructs can impact how we might think a student will persevere with a challenging task.

\section{METHODS}

This study was designed to investigate students' perspective on phenomena related to perseverance and their perseverant actions within specific problem-solving boundaries. Working with 11 students, I collected qualitative data from one-on-one think aloud problem-solving interviews and interviews of students' reflections on their problem-solving. I worked with a small number of participants in order to capture the student point of view in detail. In this article, I focus on the experiences of three representative students (Bree, Ryan, and Robert - pseudonyms), a subset of participants that exemplify three distinct trends across the full dataset. I describe these students' perseverance toward their perceived achievement goal on a challenging mathematical task for which they all affirmed interest.

\section{Participants and Context}

Participants in this study were ninth-graders in a rural, Mid-Atlantic high school. All participants came from the same section of Algebra 2 with the same teacher. Each student had successfully passed an Algebra 1 course in the prior school year. I recruited participants first by establishing a comfort level with potential volunteers. I visited the site five times, observed classes, talked informally with students, and ultimately asked if any ninth-graders in the class were interested in working on an unfamiliar mathematics problem and discussing their experience. During these informal visits, 11 students reported great interest in working with challenging mathematics problems and volunteered to participate. According to the classroom teacher, each of these 11 participants had demonstrated similar capabilities with algebraic problem-solving in their current Algebra 2 class. In these ways, these volunteers were appropriate participants in a study on perseverance because they have had similar mathematics experiences, achievements, and interests relative to algebra. Algebra in the middle grades is often considered a critical gatekeeper course to higher-level mathematics (Adelman, 2006; Rickles, 2013), and thus it is important to understand perseverance within this context. 
Task: Show as much work as you can. Please do not cross out anything you write.

Imagine 5 identical bowls stacked one inside the other. The height of 1 bowl is 2 inches. The height of a stack of 5 bowls is 5 inches.

a. Write a rule that expresses the relationship between the number of bowls in a stack and the height of the stack. b. Determine the height, in inches, of a stack of 12 bowls.

Figure 1. The Bowl-Stack Task

\section{Data Sources}

Individually with all 11 participants, I conducted a one-on-one problem-solving interview and a reflection interview. The purpose of the problem-solving interview was to confirm participants' interest in solving the mathematical task (all participants had reported their general interest during my earlier informal classroom visits), and to observe the specific problem-solving actions participants exhibited while working. I began each problem-solving interview by asking each participant if they were interested in working on the mathematical task. Then, I asked each participant to think out loud as they worked, and I did not help them solve the problem in any way. These interviews lasted as long as each participant continued to work, which ranged from about 1 minute to about 15 minutes, and were audio and video recorded for analysis. The handout on which participants worked was also collected for analysis.

The mathematical task on which each participant worked during the problem-solving interview was adapted from an Algebra 1 state standardized practice test. In consultation with the classroom teacher, the bowl-stack task (see Figure 1) task was selected because (a) participants had not worked on this task before, (b) it contained basic prerequisite knowledge for which all participants had demonstrated some proficiency (according to their teacher), and (c) it was open-ended and would likely challenge participants and necessitate perseverance. For algebra students, the bowl-stack task is appropriate to help participants navigate the concepts of linear relationships, specifically rate of change and initial values. With the basic prerequisite knowledge that the height of the stack depends upon the number of nested bowls in the stack, students have free reign to employ any strategy they wish to explore these ideas and solve the problem, illustrating the lowfloor feature of the task. Students are challenged, however, when they realize that since the bowls are nested inside one another, adding a bowl to the stack does not increase the height of the stack by the overall height of the bowl. Though features of the task can be solved using some algebraic procedures (i.e., slope formulas), these pathways are not explicitly suggested, nor are they obvious. Instead, students need to engage with the conceptual ideas that underlie such procedures to solve the problem.

Immediately following the problem-solving interview, I used a semi-structured interview protocol to solicit participants' reflections on their experiences working on the bowl-stack task. The primary purpose of the reflection interview was to listen to the participant's point of view about the achievement goal(s) they brought to this problem-solving situation which required perseverance. These interviews lasted between 30 and 60 minutes and were audio recorded and transcribed for analysis. Questions addressing participants' goals were informed by Elliot and McGregor's (2001) achievement goal scale. The interview questions were designed to be exploratory, that is, spark a conversation about the participant's experiences. Among others, introductory interview questions included: what would you like to share with me about your experiences working on this task?, how did it feel to work on this task?, what are some positives or negatives you take from working on a challenging task like this? To dig deeper into participant's goals, follow up questions included: why did you keep working?, why did you stop working?, what are some of your goals during work like this?, etc.

\section{Data Analysis}

I measured participants' interest in solving the bowl-stack task by examining their problem-solving interview. Since I directly asked participants if they were interested in solving the task, I coded these responses as either affirmative or otherwise. All participants reported interest in solving the task at hand.

Relative to the goal of this study to examine a participant's perseverance, I designed and used a perseverance analytic framework (Table 1) to study a participant's problem-solving actions during their work in the problem-solving interview. The purpose of this analysis was to describe specific moments of engagement that constituted evidence of perseverance or the lack thereof. In addition to within Table 1, I describe specific examples of such evidence in the Findings section.

Because there is a need to operationalize perseverance in this context of working on a challenging mathematical task, I designed the analytic framework to reflect to the perspectives of Middleton et al. (2015), Dolle et al. (2013), the CCSSMP (2010), Carver and Scheier (2001), Gresalfi and Barnes (2015), Schoenfeld 
Table 1. Analytic Framework for Perseverance Actions

\begin{tabular}{|c|c|}
\hline Component & Description \\
\hline $\begin{array}{l}\text { Initial } \\
\text { Attempt }\end{array}$ & $\begin{array}{l}\text { Do they make a first attempt to try to solve the problem? } \\
\text { - Evidence of perseverance - enacting a strategy to engage with the problem } \\
\text { - Evidence of lack of perseverance - giving up immediately }\end{array}$ \\
\hline First Effort & $\begin{array}{l}\text { In what ways are they spending effort to try to solve the problem? } \\
\text { - Evidence of perseverance - diligent effort via hypothesizing, exploring, guessing and checking, } \\
\text { considering multiple representations } \\
\text { - Evidence of lack of perseverance - undiligent effort via guessing without checking, writing to fill space } \\
\text { on the page, ignoring challenging aspects of the problem }\end{array}$ \\
\hline $\begin{array}{l}\text { Progress } \\
\text { Awareness }\end{array}$ & $\begin{array}{l}\text { Are they making progress? Are they aware of their progress? } \\
\text { - Evidence of perseverance - aware of mathematical progress from their efforts; using mathematical } \\
\text { justifications to guide engagement } \\
\text { - Evidence of lack of perseverance - not aware of mathematical progress from their efforts; using } \\
\text { consequential justifications to guide engagement }\end{array}$ \\
\hline $\begin{array}{l}\text { Additional } \\
\text { Attempt(s) }\end{array}$ & $\begin{array}{l}\text { Do they make an additional attempt to try to solve the problem, after their first attempt is not completely } \\
\text { successful? } \\
\text { - Evidence of perseverance - enacting a new strategy, different from the first, to reengage with the } \\
\text { problem somehow } \\
\text { - Evidence of lack of perseverance - does not make an additional attempt; giving up after initial attempt }\end{array}$ \\
\hline $\begin{array}{l}\text { Additional } \\
\text { Effort }\end{array}$ & $\begin{array}{l}\text { In what ways are they continuing to spend effort to try to solve the problem? } \\
\text { - Evidence of perseverance - diligent effort via hypothesizing, exploring, guessing and checking, } \\
\text { considering multiple representations } \\
\text { - Evidence of lack of perseverance - undiligent effort via guessing without checking, writing to fill space } \\
\text { on the page, ignoring challenging aspects of the problem }\end{array}$ \\
\hline $\begin{array}{l}\text { Additional } \\
\text { Progress } \\
\text { Awareness }\end{array}$ & $\begin{array}{l}\text { Are they making additional progress? Are they aware of their additional progress? } \\
\text { - Evidence of perseverance - aware of mathematical progress from their additional efforts; using } \\
\text { mathematical justifications to guide engagement } \\
\text { - Evidence of lack of perseverance - not aware of mathematical progress from their additional efforts; } \\
\text { using consequential justifications to guide engagement }\end{array}$ \\
\hline
\end{tabular}

(1992), and Polya (1971) regarding what actions constitute perseverance. Put simply, this perseverance lens considers if an individual enters the problem, if and how they sustain their engagement, and the outcome of such efforts. This entrance-sustain-outcome sequence is used for all attempts at solving the problem (e.g., the first attempt, amending the plan and making a second attempt, etc.). This analysis is not meant to label participant work as perseverant or not, per se, but instead to provide descriptions of specific moments of problem-solving that demonstrate states of perseverance. Also, this perspective on perseverance is not dependent on completely solving a problem correctly. A participant could demonstrate a perseverant outcome of their effort by obtaining a completely correct answer, or also by making mathematical progress toward better understanding the present mathematical relationships in some way. For context, I also noted the overall time spent working on the task. For each participant, I watched the video of the problem-solving interview numerous times to note evidence for each perseverance component in the framework, essentially describing the ways in which each participant persevered and the ways in which they did not.

Relative to the goal of this study to ascertain a participant's achievement goals, I also used an achievement goals analytic framework (Table 2) to study a participant's perceived goals during problem-solving situations requiring perseverance reported in their reflection interview. The purpose of this analysis was to describe the goal for working in such situations, from the participant's perspective. In addition to within Table 2, I describe specific examples of participant's goal perceptions in the Findings section. This framework follows closely Elliot and McGregor's (2001) 2x2 achievement goal framework, considering categories of mastery and performance and subcategories of approach and avoidance.

Coding the problem-solving and reflection interviews consisted of two examinations of each data source, noting whether and how each component of each analytic framework was evident. Regarding the framework for perseverance actions, my first examination of the video of a participant's problem-solving interview consisted of coding specific moments as affirming or non-affirming evidence of whether they made an Initial Attempt at solving, sustained a First Effort at solving, and showcased Progress Awareness as a result of their engagement. If a participant's first attempt was not successful, I coded specific moments as affirming or contrasting evidence of whether they made an Additional Attempt at solving, sustained an Additional Effort at solving, and showcased Additional Progress Awareness as a result of their additional engagement. My second examination of a problem-solving interview video consisted of descriptively coding exactly how a participant demonstrated evidence for each component of the perseverance actions framework. 
Table 2. Analytic Framework for Achievement Goals (adapted from Elliot \& McGregor, 2001)

\begin{tabular}{|c|c|c|c|}
\hline & & Definition & \\
\hline & & Mastery & Performance \\
\hline \multirow{2}{*}{ Valence } & Approach & $\begin{array}{l}\text { Pursuing intrapersonal success } \\
\text { - Evidence - aspiring to improve } \\
\text { one's own understanding }\end{array}$ & $\begin{array}{l}\text { Pursuing interpersonal success } \\
\text { - Evidence - aspiring to surpass, best, or impress a } \\
\text { peer }\end{array}$ \\
\hline & Avoidance & $\begin{array}{l}\text { Evading intrapersonal failure } \\
\text { - Evidence - aspiring to prevent } \\
\text { one's own misunderstanding }\end{array}$ & $\begin{array}{l}\text { Evading interpersonal failure } \\
\text { - Evidence - aspiring to prevent being surpassed, } \\
\text { bested, or outdone by a peer }\end{array}$ \\
\hline
\end{tabular}

Table 3. Participant Summary: Observed Perseverant Actions and Self-reported Achievement Goals

\begin{tabular}{|c|c|c|c|c|c|c|c|}
\hline Participant & $\begin{array}{c}\text { Initial } \\
\text { Attempt }\end{array}$ & $\begin{array}{c}\text { First } \\
\text { Effort }\end{array}$ & $\begin{array}{c}\text { Progress } \\
\text { Awareness }\end{array}$ & $\begin{array}{c}\text { Add. } \\
\text { Attempt(s) }\end{array}$ & $\begin{array}{c}\text { Add. } \\
\text { Effort }\end{array}$ & $\begin{array}{c}\text { Add. Progress } \\
\text { Awareness }\end{array}$ & Ach. Goal \\
\hline Bree & $\checkmark$ & $\checkmark$ & $\checkmark$ & $\checkmark$ & $\checkmark$ & $\checkmark$ & MAp \\
\hline Joseph & $\checkmark$ & $\checkmark$ & $\checkmark$ & $\checkmark$ & $\checkmark$ & $\checkmark$ & MAp \\
\hline Juanita & $\checkmark$ & $\checkmark$ & $\checkmark$ & $\checkmark$ & $\checkmark$ & $\checkmark$ & MAp \\
\hline Britney & $\checkmark$ & $\checkmark$ & $\checkmark$ & $\checkmark$ & $\checkmark$ & $x$ & MAp \\
\hline Ryan & $\checkmark$ & $\checkmark$ & $\checkmark$ & $\checkmark$ & $\checkmark$ & $\checkmark$ & $\mathrm{PAp} / \mathrm{PAv}$ \\
\hline Alison & $\checkmark$ & $\checkmark$ & $x$ & $\checkmark$ & $\checkmark$ & $x$ & $\mathrm{PAp} / \mathrm{PAv}$ \\
\hline Mary & $\checkmark$ & $\checkmark$ & $\checkmark$ & $x$ & $x$ & $x$ & $\mathrm{PAp} / \mathrm{PAv}$ \\
\hline Robert & $\checkmark$ & $\checkmark$ & $x$ & $x$ & $x$ & $x$ & MAp \\
\hline Lucy & $\checkmark$ & $\checkmark$ & $x$ & $x$ & $x$ & $x$ & MAp \\
\hline Alice & $\checkmark$ & $x$ & $x$ & $x$ & $x$ & $x$ & MAp \\
\hline Leo & $\checkmark$ & $x$ & $x$ & $x$ & $x$ & $x$ & MAp \\
\hline
\end{tabular}

$\checkmark=$ affirming evidence; $\boldsymbol{x}=$ no affirming evidence

MAp = Mastery-Approach; PAp = Performance-Approach; PAv = Performance-Avoidance

Regarding the achievement goals framework, my first and second examinations of a participant's reflection interview consisted of a similar process to determine whether and how, respectively, they made clear the definition and valence of their achievement goals while engaging with the task. Thus, I did not survey participants directly about their achievement goals in this context, but rather relied on listening to participants' voices to infer achievement goals from responses to reflection interview questions (see Urdan \& Mestas, 2006). Inter-rater reliability was established for all of the aforementioned coding decisions. To calculate reliability, I compared my analysis decisions of approximately $10 \%$ of the interviews with that of an independent coder's. We achieved an initial $86 \%$ average agreement and all disagreements were discussed and resolved collaboratively.

After all coding was complete, I compared and contrasted all 11 participants' experiences with the bowlstack task. Since all 11 participants affirmed interest, I specifically compared and contrasted participants' achievement goal and perseverance data (see Table 3 for summary). Three main trends that described the apparent relationship between reported achievement goals and observed perseverance in problem-solving were apparent. The trends were: (a) four participants reported mastery-approach goals and demonstrated ample evidence of perseverance, (b) three participants simultaneously reported performance-approach and performance-avoidance goals and demonstrated some evidence of perseverance, and (c) four participants reported mastery-approach goals and demonstrated limited evidence of perseverance. I chose Bree, Ryan, and Robert as representative participants of these three trends, respectively, because their interview data was rich and they best described the collective experiences of their peers. I present these trends as profiles of student in-the-moment states of engagement. Detailing and comparing these profiles help answer the research questions that guided this qualitative investigation.

\section{FINDINGS}

For ninth-grade algebra students interested in solving a challenging mathematical task requiring perseverance, the research questions that guided this investigation considered how participants described their achievement goals and how they subsequently persevered, if at all, during their engagement with the bowl-stack task. The experiences of Bree, Ryan, and Robert represent distinct profiles of perseverance that illuminate three trends across the full dataset. The observed actions and reported goals of these three participants illustrated three compelling pictures of a ninth-grader's perseverance in the context of working on a challenging mathematical task. In this section, I describe evidence of each student's perseverance on the bowl-stack task and their self-reported goals guiding such efforts (see Table 4 at the end of the Findings 
Table 4. Summary: Observed Perseverance Actions and Self-Reported Achievement Goals guiding Engagement

\begin{tabular}{|c|c|c|}
\hline Participant & Actions & Goals \\
\hline $\begin{array}{c}\text { Bree } \\
\text { Effort for } \\
\text { Understanding }\end{array}$ & $\begin{array}{l}\text { Summary - ample evidence of perseverance } \\
\text { Initial Attempt: tried to make sense of the stack of bowls } \\
\text { First Effort: wrote and explored a proportion } \\
\text { Progress Awareness: no mathematical awareness, only } \\
\text { consequential awareness of proportion strategy shortcom } \\
\text { Additional Attempt: focused on the initial height of the } \\
\text { bottom bowl with picture } \\
\text { Additional Effort: explored linearity, wrote } \\
\text { an equation (made error in writing slope), } \quad y=\frac{4}{3} x \\
\text { found the height of a stack of } 12 \text { bowls } \\
\text { Additional Progress Awareness: mathematical } \quad y=\frac{4}{3}(1 t) \\
\text { awareness of linearity, no mathematical } \\
\text { awareness of error } \\
\quad \text { Total time: } 12 \text { minutes and } 1 \text { second } \\
\end{array}$ & $\begin{array}{l}\frac{1}{2} \cdot \frac{5}{5} \quad \begin{array}{c}\text { Mastery- } \\
\text { Approach }\end{array} \\
\text { aings } \\
+2 \quad \frac{4}{3} \frac{11}{1} \\
+2 \quad \frac{4}{3}+\frac{33}{3}=\frac{37}{3}=12 \frac{1}{1 / 3}+2\end{array}$ \\
\hline $\begin{array}{l}\text { Ryan } \\
\text { Play to Win }\end{array}$ & $\begin{array}{l}\text { Summary - evidence of perseverance, but gave up abrur } \\
\text { finishing task } \\
\text { Initial Attempt: tried to make sense of the five bowls } \\
\text { separately with a picture } \\
\text { First Effort: imagined the stack of bowls, guessed and } \\
\text { checked different values for the rate of change } \\
\text { Progress Awareness: mathematical awareness of guess- } \\
\text { and-check strategy shortcomings } \\
\text { Additional Attempt: drew new picture of bowl stack } \\
\text { Additional Effort: reasoned about the rate of change, } \\
\text { wrote an equation (correct), stopped working and did } \\
\text { not find the height of a stack of } 12 \text { bowls } \\
\text { Additional Progress Awareness: mathematical } \\
\text { awareness of why linear equation worked } \\
\text { Total time: } 9 \text { minutes and } 11 \text { seconds }\end{array}$ & 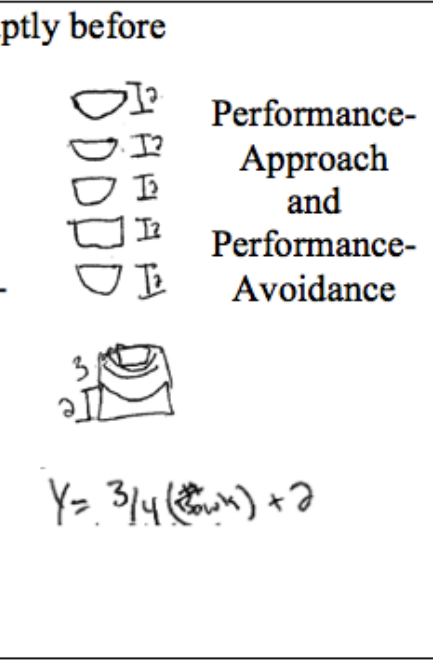 \\
\hline $\begin{array}{c}\text { Robert } \\
\text { Anything Is } \\
\text { Enough }\end{array}$ & $\begin{array}{l}\text { Summary - limited evidence of perseverance } \\
\text { Initial Attempt: wrote the given information, tried to } \\
\text { make sense of the stack of bowls } \\
\text { First Effort: wrote and solved an equation based on } \\
\text { given values, stopped working and did not write a rule } \\
\text { or find the height of a stack of } 12 \text { bowls } \\
\text { Progress Awareness: no mathematical awareness, } \\
\text { only consequential awareness of equation strategy } \\
\text { shortcomings } \\
\text { Additional Attempt: } \mathrm{n} / \mathrm{a} \\
\text { Additional Effort: } \mathrm{n} / \mathrm{a} \\
\text { Additional Progress Awareness: } \mathrm{n} / \mathrm{a} \\
\quad \text { Total time: } 1 \text { minute and } 47 \text { seconds }\end{array}$ & $\begin{array}{l}\text { Iboul-2inche } \\
5 \text { bowi-10,inces } \\
5 \text { stacked-5inches Approach }\end{array}$ \\
\hline
\end{tabular}

section for summary). I used these perspectives to inform profiles of perseverance states. Such states of engagement are not inert traits of these students, but a collection of in-the-moment mindsets, motives, and actions potentially living within all students that can be brought to the surface in certain contexts (Goldin, Epstein, Schorr, \& Warner, 2011). The names of each profile were informed by in-the-moment participant quotes during data collection. 


\section{$\frac{1}{2} \quad \frac{5}{5}$}

Figure 2. Evidence of Bree's First Effort: Exploring two ratios

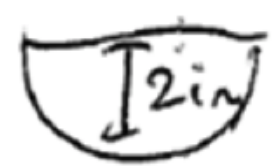

Figure 3. Evidence of Bree's Additional Attempt: Drawing the initial height of the bowl

\section{Bree - Effort for Understanding}

Participant Bree exemplifies a ninth-grade student who showed ample evidence of perseverance while working on the bowl-stack task, driven by her goals of mastery. Including Bree, 4 out of 11 participants in this study generally engaged with the task in these ways. Thus, Bree represented the perseverance profile Effort for Understanding. Bree's achievement goals were mastery-approach and her perseverant actions indicated multiple diligent and productive efforts despite challenges and setbacks. Before working, Bree affirmed she generally liked challenges and found the bowl-stack interesting.

\section{Perseverant actions: Diligent and productive first and additional efforts}

During her problem-solving interview, Bree demonstrated ample evidence of perseverance as she worked on a problem for which she did not immediately know a solution. She began by thinking about the problem context, gesturing with her hands the bowls stacked one inside the other as well as the initial height of one bowl. She said, "Ok, the bowls are inside of each other like in a cabinet. The bottom bowl gets as high as 2 inches, but there is a stack after that." This was evidence of Bree making an initial attempt to enter the problem by spending effort to make sense of the context.

After thinking about the bowl-stack, Bree said "I almost think I could do a proportion here" and starts writing down some ideas (see Figure 2). She thought aloud, "I know the 1 over 2 could be one bowl and two inches, and then the 5 bowls and 5 inches." This was evidence of Bree exploring her first strategy by thinking about some values from the problem situation in two ratios and considering the reasonableness of her setup. Next, Bree decided this approach was not working and abandons this strategy, "Wait, I don't think this is making any sense. This doesn't include a variable or anything. I'm going to do something else." Bree realized that her proportional reasoning setup was not helping her solve the problem, but she did not articulate she understands exactly the mathematical reason. Therefore, this was evidence of consequential awareness to justify her decision to change course.

Bree amended her original plan of using a proportion to more carefully think about how the first bowl creates an initial height, and then additional bowls start adding to the height. She drew a picture of the bottom bowl (see Figure 3) and continued to think aloud about how she might proceed. She said, "I know that the bottom is 2 inches high, and I know that I will be adding to it each time. I just have to figure out what equation." This was evidence of Bree making an additional attempt to solve the problem, after her first attempt had failed.

Bree continued to think about what to do next, and then had a breakthrough, "Wait, I can try $y=m x+b$ to do this. The $\mathrm{b}$ can be the 2 inches and the $\mathrm{m}$ can be the little bit each time, the changing part." Next, she thought about the value of the slope and concludes, "when I add 3 bowls it goes up 4 inches, so $4 / 3$. ." Unfortunately, she was mistaken because the problem context is adding 4 bowls to increase the height by 3 inches. Nevertheless, Bree demonstrated diligence as she recognizes the linearity of the situation and worked hard to develop an equation that models this. She went on to solve both parts of the problem, albeit incorrectly since her slope was 4/3 rather than 3/4 (see Figure 4). Bree showed some evidence of awareness of mathematical progress since she understood why a linear model in slope-intercept form is appropriate. However, this was not a full mathematical justification because she was unaware she misspoke and made a small error. Still, Bree's in-the-moment engagement with the bowl-stack task demonstrated perseverance through making multiple, diligent attempts to solve the problem while making some mathematical progress. Bree spent 12 minutes and 1 second working on this problem. 


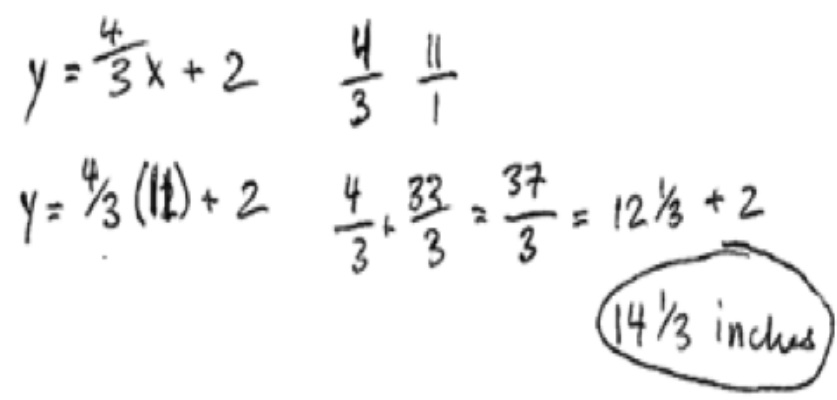

Figure 4. Evidence of Bree's Additional Effort: Finding the height of a stack of 12 bowls

\section{Achievement goals: Mastery-approach}

During her reflection interview, Bree revealed her objectives during problem-solving with challenges that are consistent with adopting mastery-approach goals. She explained, "On problems like this I like to solve myself, instead of being told how to solve it. It's like a puzzle." She went on, "[If I don't understand something] I will try harder, make sure I understand it. I want to know how it works." Bree's aim to understand why challenging mathematics works the way it does - and to self-regulate her effort to achieve that objective provided signs of adopting mastery-approach goals when approaching such challenging mathematical tasks. Related to her mastery-approach goals, Bree revealed aspects of her mindset during challenging mathematical situations. While reflecting on the bowl-stack task, Bree shared "Even though I didn't figure it out right away, I was confident that I could understand it." She went on, "And when you're moving through the problem it feels good, even if it ends up being not right." Bree's reported disposition toward challenges suggests she was comfortable making mistakes and viewed them as an educative step toward mastery.

\section{Effort for understanding}

Evidence from representative participant Bree's engagement with the bowl-stack task in conjunction with her self-reported achievement goals in such situations suggested a perseverance profile called Effort for Understanding. In short, this state represents a case of a perseverant learner that we would hope to see. Students acting in this state leverage hard work in uncertain situations to strive toward mastery, willing to overcome obstacles along the way. From the researcher perspective, this profile plays out as many might predict: there exists a symbiotic relationship between perseverance in the moment and adopting masteryapproach goals (Elliot \& McGregor, 2001; Middleton et al., 2015). Such a relationship can encourage teachers to provide opportunities for students to engage in perseverant work to help promote the development of mastery goals (e.g., the Train Problem in Bass \& Ball, 2015), or to design environments that stimulate mastery goal orientations to help facilitate student perseverance with challenges (e.g., incorporating project-based learning, Krajcik \& Shin, 2014).

\section{Ryan - Play to Win}

Participant Ryan illustrates a ninth-grade student who spent effort to persevere on the bowl-stack task, as long as he believed his effort will lead to a right answer. Ryan's achievement goals varied between performance-approach and performance-avoidance and his perseverant actions indicated multiple diligent and productive efforts despite discouragements. Including Ryan, 3 out of 11 participants in this study generally engaged with the task in this fashion. In these ways, Ryan represented the perseverance profile Play to Win. Similar to Bree, Ryan shared how he found the bowl-stack task interesting and worthwhile to solve.

\section{Perseverant actions: Diligent and productive first and additional efforts}

While beginning to work in his problem-solving interview, Ryan mentioned how this problem seems challenging because he is not initially sure what to do. He started by re-reading the problem multiple times and underlining the following sentences: "The height of 1 bowl is 2 inches. The height of a stack of 5 bowls is 5 inches." He eventually began by drawing a picture of 5 bowls, unstacked, each measuring 2 inches high (see Figure 5). He says, "Ok so 5 bowls will total 10 inches." This visual was evidence of Ryan making an initial attempt to enter the problem. 


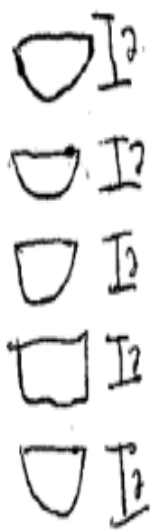

Figure 5. Evidence of Ryan's Initial Attempt: Drawing five bowls separately

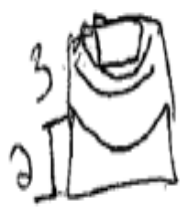

Figure 6. Evidence of Ryan's Additional Attempt: Drawing a bowl stack

He planned his attack by deciding to imagine the stack of bowls. He said, "I have to find that space (gesturing a space between his thumb and forefinger)," implying the distance between each stacked bowl. Ryan continued to think aloud and started to guess and check different values for the rate of change. He first guessed $2 / 3$ because "the bottom bowl equals 2 inches and there is 3 more inches to go until you get to the top." He realized his guess does not make sense when he said "it doesn't represent the little piece of the bowl that would be showing." Ryan made a second guess of 1 inch and checked to see if his answer made sense. He said, "That equals 4 inches if only half the bowl is showing, so that would put me over." Ryan then realized that the rate of change will be less than one, and became convinced that guessing and checking was not the best way to get his answer, so he decided to try a different strategy. Ryan's efforts to this point were evidence of diligent exploration of his first strategy, especially because he was constantly considering the reasonableness of his work. Thus, Ryan's decision to abandon his first strategy was justified by mathematical awareness of his progress.

Ryan amended his plan by drawing a new picture of an initial bowl and a stack of four bowls inside it (see Figure 6). He labeled heights of 2 and 3 inches, respectively. This was evidence of Ryan making an additional attempt to solve the problem, after his first effort did not lead to a correct answer. Ryan began to focus more purposefully on rate of change in context. He said, "I have to find that little difference (points to the distance between each stacked bowl in his picture)...that little piece of the bowl showing." He continued to think aloud, saying, "When you put 5 bowls together it equals 5 inches and then there are 4 bowls that I have to get into 3 , so there is 3 inches and I need to get 4 more bowls into there." He continued thinking, and finally found the correct rate of change. He said, "So that little piece is three over four, or three quarters of an inch. And that will work because 5 bowls is 5 inches."

Ryan finished his thought by writing a correct equation, $y=3 / 4$ (\# of bowls)+2 (see Figure 7). He then tried to finish the problem by using his equation to find the height of a stack of 12 bowls, but abruptly gave up after he had trouble multiplying $3 / 4$ by 11 without a calculator. Upon giving up, Ryan said, "I'm not very good at doing math in my head. I'm not really sure about this." Although Ryan did not technically finish the problem, he still displayed evidence of diligent exploration of his second strategy by using a new, more precise drawing to focus more intently on the situational rate of change. It was also evident that Ryan has made mathematical progress, especially since he could explain exactly how this stack of bowls is increasing by three quarters of an inch each time he adds a bowl to it. Ryan's actions in the moments defining his work on the bowl-stack task exemplified perseverance through overcoming obstacles and making mathematical progress through his efforts. Ryan spent 9 minutes and 11 seconds working on the task. 


\section{$y=3 / 4(30,4)+2$}

Figure 7. Evidence of Ryan's Additional Effort: Writing an equation

\section{Achievement goals: performance-approach and performance-avoidance}

During his reflection interview, Ryan discussed his achievement goals during problem-solving that are in concert with both performance-approach and performance-avoidance. Most clearly, Ryan explained how he is driven to out-perform his peers while working on challenging mathematics problems, "[In class I'm a] competitive person so that's just a goal I'd like to achieve, being the best at solving the problem." Reflecting on his bowl-stack work, Ryan revealed that his initial goal was "to win...to get it right." In these ways, Ryan seemed motivated to be known as the best problem-solver amongst his peers. However, he went on to describe how his competitiveness diminishes when he runs into obstacles. He explained, "I don't like to lose...coming back from a failure it drops my confidence...it would kill my motivation to even keep going and trying to figure it out." According to Ryan, his effort seemed to hinge on whether he expects to "win" or "lose". Ryan also shared a glimpse into his attitude toward uncertainty and effort during his reflection interview. He stated, "I like problems like this when I get them [correct]. It feels good, it's like a win." He went on to describe how he feels when he gets confused during these situations, "I'd say I get a little more discouraged and frustrated and then I no longer feel the need to win because I'm mad because I don't how to do it or I'm struggling with what I'm doing." Ryan added that "it would feel crushing" to fail at a task on which he was expending some effort. Through the point of view of competition, Ryan's testimony depicted a clear picture of a dichotomous performance-goal orientation in this context.

\section{Play to win}

Representative participant Ryan's observed actions with the bowl-stack task and related reflections are illustrative of how one student can self-report striving toward multiple achievement goals within the same experience: performance-approach and performance-avoidance. These findings help represent a perseverance profile called Play to Win. Students acting in this state are constantly driven by their expectation of success or crippled by their fear of failure. If success is perceived as likely, a student in this state is willing to spend effort exploring uncertain mathematics because they anticipate the gratifying victory in the end. However, if the perceived likelihood of success shifts, the same student may disengage entirely to protect their ego and avoid defeat. Students operating in this state can still encounter and overcome obstacles, but the nature of such obstacles can dictate dramatic swings of perseverance. Ryan initially looked the part of a motivated problem solver, yet bubbling under the surface was instability and unwillingness to struggle. Ryan decided to persevere while wrestling with finding the correct slope, likely because he still felt confident in his chances at a win. Yet when he anticipated trouble multiplying fractions without a calculator he gave up almost instantly, suggesting an avoidance of any failures despite his progress. From the researcher perspective, this profile demonstrates the instability of one's performance goal orientations and perseverance within one particular situation. Ryan demonstrated how enacting performance-approach goals can fleetingly transform into performance-avoidance goals and have ramifications on one's subsequent perseverance. Such dynamics can inspire teachers to recognize performance goal orientations in their own students. Teachers can work to help redefine what it means to win or lose in the context of working with challenging mathematics, and promote an environment that prizes effort over achievement to encourage more stable perseverance (Dweck, 2006).

\section{Robert - Anything Is Enough}

Participant Robert represents a ninth-grade student who demonstrated scarce evidence of perseverance on the bowl-stack task. Surprisingly, Robert reported being driven by mastery-approach goals on this task, yet he exhibited very little evidence of diligence and productivity in his single effort at solving. Including Robert, 4 out of 11 participants in this study engaged in these ways with the task. Robert's experience represents the perseverance profile Anything Is Enough. Akin to Bree and Ryan, Robert reported being captivated by the bowl-stack task and found it interesting.

\section{Perseverant actions: Little diligence and productivity in first effort, no additional effort}

Robert began his work by re-reading the task. He said, "I'm going to keep reading it to figure out what I need to know." He wrote down the given information (see Figure 8) and said "I know what I need to find. I 


\section{$\mid$ bowl-2inche \\ 5 bowl-loinches. \\ 5 stacked-5inches}

Figure 8. Evidence of Robert's Initial Attempt: Writing the given information

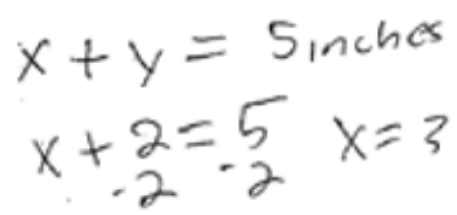

Figure 9. Evidence of Robert's First Effort: Writing and solving an equation

get that. I'm just not sure how to do it. I know that 5 bowls would be 10 inches, but they're stacked so it's only 5 inches." Robert was trying to make sense of the situation, thus making an initial attempt to enter the problem.

Robert started to write down some equations he thought might help him model the scenario (see Figure 9). He wrote $x+y=5$ while saying, "I remember some equations I used to use back in my other grades." Next, Robert substituted $\mathrm{y}=2$ into his equation and solved for $\mathrm{x}$, obtaining $\mathrm{x}=3$. He explained why he was doing this, stating "There is a 2 and 5 in the problem, so I will try those numbers." Afterwards, he said, "This isn't working, I just don't know how to put all this together" and put his pen down to indicate he was finished working. Robert did not make a second attempt to try and solve this problem. In total, Robert spent 1 minute and 47 seconds working on this problem.

Although Robert tried to model the situation with an equation and briefly explored his strategy, he disengaged quickly from his efforts and revealed during his reflection interview that he was "just trying things to get something down on paper." Also, he did not articulate he understood exactly why his strategy was not helping him. Therefore, Robert showcased little evidence of diligent exploration of his first strategy and no evidence of awareness of any mathematical progress. Ultimately, Robert demonstrated consequential awareness alone by recognizing his plan was flawed to justify his decision to stop working.

\section{Achievement goals: Mastery-approach}

In his reflection interview, Robert shared how his attitude towards challenging mathematics motivated his achievement goals - goals aligned with mastery-approach. Robert revealed his primary goal during his work on the bowl-stack problem, "I wanted to test my knowledge...to push myself through it and try to solve it." Robert added, "I like to try [to figure things out] myself, I'm curious. I'm determined, like, I can do this. I'm going to keep trying, keep going at it." Robert's testimony demonstrated his adoption of mastery-approach goals in this context because he is passionate about learning challenging mathematics for himself. Moreover, Robert reported he was willing to spend the necessary effort to overcome any obstacles in his way. As Robert continued to reflect on his bowl-stack experience, he shared how satisfied he was with his effort toward accomplishing his goals. He said, "I didn't let my faults keep me down. Like I wanted to give up at times but I'm glad I stuck with it. You have to stick with it to get anywhere in problems like this." In general, Robert was pleased with his perseverance on the bowl-stack task. When asked about the source of his satisfaction, Robert explained, "Your teachers are always telling you to try new things and not give up. So this was good idea, I'm happy I did this and I feel good about it, you know?...I'm kind of happy I got to do this problem." In sum, Robert was proud of his effort on the bowl-stack task and reported goals of mastery-approach in conjunction with a productive disposition in the context of working on challenging mathematical tasks.

\section{Anything is enough}

In Robert's representative case, observed actions coupled with self-reported reflections inform a perseverance profile called Anything Is Enough. This state exemplifies how a student's perceptions of their problem-solving actions may not align with a teacher's (or researcher's) perception of the student's actions in the context of persevering toward particular achievement goals. Students acting in this state may have honest intentions toward mastery and facilitative attitudes toward effort, yet hold a distorted view of what counts as 
productive effort. Distorted, that is, relative to the opinion of educators. Most mathematics educators would agree that Robert's effort on the bowl-stack task was not indicative of perseverance toward a goal of mastery, yet Robert's personal satisfaction with his efforts paints a different picture.

In this state, any effort is enough when facing an uncertain obstacle. Simply engaging with a challenge for even a matter of moments is perceived as a success, regardless if progress is made or noticed. Robert admitted that most of his written work on the bowl-stack task was to just "get something down on paper," and his pride persists because his paper is not blank. In these ways, individuals acting in this state hold a student-ing (Aaron, 2011; Fenstermacher, 1986) conception of what it means to persevere. In the context of working on a challenging mathematical task, students can rationalize minimal effort spent and believe it is productive because they perceive the norm that all a good student needs to do is at least make an attempt. Robert gave some insight into a potential source of these norms when he mentioned how his teachers consistently encouraged approaching challenges and not giving up. His teachers praised his efforts, not outcomes, to establish a challenge-seeking environment (Mueller \& Dweck, 1998). Yet, perhaps these teacher encouragements are being interpreted in a binary way: you can either try or not try, there is no in-between. Robert's story suggests he thought he was persevering because he simply wrote something down (he tried), and unfortunately - despite his feelings of satisfaction in these moments of challenge - this conception is not serving his goals of learning mathematics for mastery and understanding. Teachers can work to establish norms that redefine what it means to persevere by adopting a continuum of effort, making explicit that there exists a difference between superficial effort and intellectual effort in the context of working toward mastery in a mathematical domain (see Carbonaro, 2005).

\section{DISCUSSION}

Participants' observed actions and reported achievement goals and experiences with a challenging mathematical task revealed three divergent perspectives illustrative of how and why a ninth-grade algebra student might persevere in the face of mathematical obstacles. Bree's representative experience depicted a close-to-ideal scenario for perseverance, somewhat indicative of what research on mastery goals may predict to happen in this context (see Elliot, 2005). Ryan's representative experience may also be predicted from research on performance goals (see Furner \& Gonzalez-DeHass, 2011; Urdan \& Mestas, 2006), yet his abrupt swings along the approach-avoid dimension illustrated the fluctuating nature of achievement goal motivation during engagement with a single task. Robert's representative experience, on the other hand, is surprising and completely divergent from what research might predict. He showed how acting under mastery-approach goals can drive behavior that is less productive than we might expect. Robert embodied how someone could view themselves as an ideal perseverant learner, but would benefit from pushing themselves further. The profiles of Effort for Understanding, Play to Win, and Anything Is Enough suggested that goals for and conceptions of perseverant work may not be the same for all students involved. Most educators adhering to current mathematical standards of practice agree developing student perseverance is important to promote learning with understanding, yet students demonstrating perseverance may not be striving toward the same mastery goal.

The student experiences shared in this paper illustrated relationships between achievement goals and problem-solving actions, some of which are relationships not currently represented in prior research (see Robert's representative experience). Perseverant actions may not always be aligned to goals of mastery, and the fragility of perseverant engagement is evident when underlying goals of outperforming others are positioned in the crosshairs. Thus, a more critical eye from classroom teachers is needed, being careful not to assume observed perseverance is evidence of a more stable mastery goal orientation - there may be other motivators lurking that can disrupt productive effort. The findings also show that although students may report being motivated by mastery goals, they may not be fully aware how to achieve them. Teachers inspiring students to adopt a growth mindset and to not give up at the first sign of mathematical struggle may be inadvertently encouraging a perfunctory understanding of what it means to persevere. Students may exert minimum effort to check-the-box of perseverance and feel proud of their work, but not make real mathematical progress. Although a coveted outcome in classrooms is student pride and satisfaction, it should be genuine and serving the student's learning (Pekrun, 2006). Students need concrete strategies and specific support to learn what it means to hold a positive mathematical disposition and problem-solve accordingly (Yeager \& Walton, 2011). Thus, teachers should be explicit about what counts as perseverance and help students realize the difference between minimal and meaningful effort in the learning process. 


\section{Limitations and Future Research}

Each participant experience reported here existed within a specific context: clinical interviews with volunteers during and after engagement with one mathematics problem. Studying volunteers insured students would be generally interested in the problem and willing to engage with challenges. In a naturalistic classroom setting, more effort might be needed to capture the interest of all students. Additionally, results could look different if participants engaged with different tasks. Thus, future research should include problemsolving and reflection interviews across multiple tasks, with a pre-test of participants' mathematics knowledge informing task selections. Moreover, the representative experiences of Bree, Ryan, and Robert introduce hypotheses that should be investigated, specifically the prevalence of these perseverance profiles. For instance, how prevalent are profiles like Robert's? I was genuinely surprised to find 4 of my 11 participants acting in an Anything Is Enough state while engaging with the bowl-stack task. Could this be a common student state of mind during times when perseverance is necessary? Answering such questions in future studies will help teachers be more aware of students in similar states, ultimately to help develop more productive angles into perseverance.

\section{CONCLUSION}

Working with students interested in the task at hand, this study explored perseverance from two angles: observed problem-solving actions and students' reported achievement goals dictating their engagement. Combining these two points of view affords fine-grained insights into how and why mathematics learners might persevere, or might not. This exploratory study showed that persevering students may have different goals in mind, and thus require different classroom supports to encourage productive engagement amidst mathematical challenges. Additionally, students may be operating with a superficial understanding of perseverance and the effort required to develop mathematical understandings. Students acting in these states require careful attention and need specific instruction about what it means to persevere with challenging mathematics. Future research further studying the complex nature of perseverance has important implications, namely helping inform teachers on ways they can cultivate more perseverant learners - a vital objective of the CCSSMP (2010).

\section{Disclosure statement}

No potential conflict of interest was reported by the authors.

\section{Notes on contributors}

Joseph DiNapoli - Montclair State University, Montclair, NJ, USA.

\section{REFERENCES}

Aaron, W. R. (2011). The position of the student in geometry instruction: A study from three perspectives (Unpublished doctoral dissertation), The University of Michigan. Available at https://deepblue.lib.umich.edu/handle/2027.42/84625

Adelman, C. (2006). The toolbox revisited: Paths to degree completion from high school through college. Washington, DC: U.S. Department of Education. Available at https://eric.ed.gov/?ID=ED490195

Ainley, M., Hidi, S., \& Berndorff, D. (2002). Interest, learning, and the psychological processes that mediate their relationship. Journal of Educational Psychology, 94(3), 545. https://doi.org/10.1037/0022-0663.94.3.545

Ainley, M., Hillman, K., \& Hidi, S. (2002). Gender and interest processes in response to literary texts: Situational and individual interest. Learning and Instruction, 12(4), 411-428.

Ames, C. (1992). Classrooms: Goals, structures, and student motivation. Journal of Educational Psychology, 84(3), 261-271. https://doi.org/10.1016/S0959-4752(01)00008-1

Ames, C., \& Archer, J. (1988). Achievement goals in the classroom: Students' learning strategies and motivation processes. Journal of Educational Psychology, 80(3), 260-267. Retrieved from http://groups.jyu.fi/sporticus/lahteet/LAHDE_10.pdf

Bandura, A. (1997). Self-efficacy: The exercise of control. New York: Freeman. 
Bandura, A. \& Schunk, D. H. (1981). Cultivating competence, self-efficacy, and intrinsic interest through proximal self-instruction. Journal of Personality and Social Psychology, 41(3), 586-598. https://doi.org/10.1037/0022-3514.41.3.586

Bass, H. \& Ball, D. L. (2015). Beyond "you can do it!": Developing mathematical perseverance in elementary school. In N. Alpert (Ed.), The Collected Papers. Chicago, IL: Spencer Foundation. Retrieved from http://www.spencer.org/collected-papers-april-2015

Blackwell, L. S., Trzesniewski, K. H., \& Dweck, C. S. (2007). Implicit theories of intelligence predict achievement across an adolescent transition: A longitudinal study and an intervention. Child Development, 78(1). 246-263. https://doi.org/10.1111/j.1467-8624.2007.00995.x

Butler, R. (1992). What young people want to know when: Effects of mastery and ability goals on interest in different kinds of social comparisons. Journal of Personality and Social Psychology, 62(6), 934-943. https://doi.org/10.1037/0022-3514.62.6.934

Carbonaro, W. (2005). Tracking, students' effort, and academic achievement. Sociology of Education, 78(1), 27-49. https://doi.org/10.1177/003804070507800102

Carver, C. S., \& Scheier, M. F. (2001). On the self-regulation of behavior. Cambridge, UK: Cambridge University Press.

Common Core State Standards Initiative (CCSSI). (2010). Common Core State Standards for Mathematics. Washington, DC: National Governors Association Center for Best Practices and the Council of Chief State School Officers.

Dewey, J. (1910). How we think. Boston: Heath.

Dolle, J. R., Gomez, L. M., Russell, J. L., \& Bryk, A. S. (2013). More than a network: Building professional communities for educational improvement. National Society for the Study of Education, 112(2), 443-463. Retrieved from http://learndbir.org/resources/14-Dolle-Gomez-RussellBryk-Ready.pdf

Duckworth, A. L., Peterson, C., Matthews, M. D., \& Kelly, D. R. (2007). Grit: perseverance and passion for long-term goals. Journal of Personality and Social Psychology, 92(6), 1087-1101. https://doi.org/10.1037/0022-3514.92.6.1087

Duda, J. L. \& Nicholls, J. G. (1992). Dimensions of achievement motivation in schoolwork and sport. Journal of Educational Psychology, 84(3), 290-299. Retrieved from https://www.researchgate.net/profile/Joan_Duda/publication/229106683_Dimensions_of_Achievement _Motivation_in_Schoolwork_and_Sport/links/Ofcfd5005568b0d772000000/Dimensions-ofAchievement-Motivation-in-Schoolwork-and-Sport.pdf

Dweck, C. S. (1986). Motivational processes affecting learning. American Psychologist, 41(10), 1040-1048. Retrieved from http://psycnet.apa.org/doi/10.1037/0003-066X.41.10.1040

Dweck, C. S. (2006). Mindset: The new psychology of success. Random House.

Dweck, C. S. \& Elliott, E. S. (1983). Achievement motivation. In E. M. Heatherington (Ed.), Handbook of child psychology: Socialization, personality, and social development. (Vol. 4, pp. 643-691). New York: Wiley.

Dweck, C. S. \& Leggett, E. L. (1988). A social cognitive approach to motivation and personality. Psychological Review, 95(2), 256-273. $\quad$ Retrieved from https://pdfs.semanticscholar.org/2592/a119a2a9b3436edc9b073d5b1aff55a824e5.pdf

Eccles, J. S. \& Wigfield, A. (2002). Motivational beliefs, values, and goals. Annual review of psychology, 53(1), 109-132. https://doi.org/10.1146/annurev.psych.53.100901.135153

Elliot, A. J. (1999). Approach and avoidance motivation and achievement goals. Educational Psychologist, 34(3), 149-169. https://doi.org/10.1207/s15326985ep3403_3

Elliot, A. J. (2005). A conceptual history of the achievement goal construct. Handbook of Competence and Motivation, 52-72.

Elliot, A. J. \& McGregor, H. A. (2001). A $2 \times 2$ achievement goal framework. Journal of personality and social psychology, 80(3), 501-519. Retrieved from http://www.realtutoring.com/phd/ElliotMcGregor2001.pdf

Fenstermacher, G. D. (1986). Philosophy of research on teaching: Three aspects. Handbook of Research on Teaching, 3, 37-49.

Festinger, L. (1957). A theory of cognitive dissonance. Evanston, IL: Row, Peterson. 
Freeburn, B. \& Arbaugh, F. (2017). Supporting productive struggle with communication moves. Mathematics Teacher, 111(3), 176-181. Available at https://www.jstor.org/stable/10.5951/mathteacher.111.3.0176

Furner, J. M. \& Gonzalez-DeHass, A. (2011). How do students' mastery and performance goals relate to math anxiety? Eurasia Journal of Mathematics, Science \& Technology Education, 7(4), 227-242. https://doi.org/10.12973/ejmste/75209

Gallagher, A. M. \& De Lisi, R. (1994). Gender differences in scholastic aptitude test Mathematics problem solving among high-ability students. Journal of Educational Psychology, 86(2), 204-211. http://psycnet.apa.org/doi/10.1037/0022-0663.86.2.204

Gresalfi, M. S. \& Barnes, J. (2015). Designing feedback in an immersive videogame: supporting student mathematical engagement. Educational Technology Research and Development, 1-22. Retrieved from https://link.springer.com/article/10.1007/s11423-015-9411-8

Goldin, G. A., Epstein, Y. M., Schorr, R. Y., \& Warner, L. B. (2011). Beliefs and engagement structures: Behind the affective dimension of mathematical learning. ZDM Mathematics Education, 43, 547-560. Retrieved from https://ink.springer.com/article/10.1007/s11858-011-0348-z

Gottfried, A. E., Marcoulides, G. A., Gottfried, A. W., Oliver, P. H., \& Guerin, D. W. (2007). Multivariate latent change modeling of developmental decline in academic intrinsic math motivation and achievement: Childhood through adolescence. International Journal of Behavioral Development, 31(4), 317-327. https://doi.org/10.1177\%2F0165025407077752

Harackiewicz, J. M., Durik, A. M., Barron, K. E., Linnenbrink-Garcia, L., \& Tauer, J. M. (2008). The role of achievement goals in the development of interest: Reciprocal relations between achievement goals, interest, and performance. Journal of Educational Psychology, 100, 105-122. https://doi.org/10.1037/0022-0663.100.1.105

Hidi, S. \& Renninger, K. A. (2006). The four-phase model of interest development. Educational Psychologist, 41(2), 111-127. https://doi.org/10.1207/s15326985ep4102_4

Hiebert, J., \& Carpenter, T. P. (1992). Learning and teaching with understanding. Handbook of research on mathematics teaching and learning: A project of the National Council of Teachers of Mathematics, 6597.

Hiebert, J., Carpenter, T. P., Fennema, E., Fuson, K., Human, P., Murray, H., Olivier, A., \& Wearne, D. (1996). Problem solving as a basis for reform in curriculum and instruction: The case of mathematics. Educational Researcher, 25(4), 12-21. https://doi.org/10.3102\%2F0013189X025004012

Hiebert, J. \& Grouws, D. A. (2007). The effects of classroom mathematics teaching on students' learning. Second Handbook of Research on Mathematics Teaching and Learning, 1, 371-404.

Kapur, M. (2010). Productive failure in mathematical problem-solving. Instructional Science, 38(6), 523-550. Retrieved from https:/link.springer.com/article/10.1007/s11251-009-9093-x

Kapur, M. (2011). A further study of productive failure in mathematical problem-solving: Unpacking the design components. Instructional Science, 39(4), 561-579. Retrieved from https://ink.springer.com/article/10.1007/s11251-010-9144-3

Karabenick, S. A. (2003). Seeking help in large college classes: A person-centered approach. Contemporary educational psychology, 28(1), 37-58. https://doi.org/10.1016/S0361-476X(02)00012-7

Karabenick, S.A. (2004). Perceived achievement goal structure and college student help seeking. Journal of Educational Psychology, 96, 569-581. http://psycnet.apa.org/doi/10.1037/0022-0663.96.3.569

Krajcik, J. S. \& Shin, N. (2015). Project-based learning. In K. Sawyer (Ed.), Cambridge Handbook of the Learning Sciences (pp. 275-297). New York: Cambridge University Press.

Kress, N. E. (2017). 6 essential questions for problem-solving. Mathematics Teacher, 111(3), 190-196. Retrieved from https://www.jstor.org/stable/10.5951/mathteacher.111.3.0190

Lepper, M. R. (1988). Motivational considerations in the study of instruction. Cognition and Instruction, 5, 289-309. https://doi.org/10.1207/s1532690xci0504_3

Linnenbrink, E. A. \& Pintrich, P. R. (2003). The role of self-efficacy beliefs in student engagement and learning in the classroom. Reading and Writing Quarterly, 19, 119-137. https://doi.org/10.1080/10573560308223

Meece, J. L., Blumenfeld, P. C., \& Hoyle, R. H. (1988). Students' goal orientations and cognitive engagement in classroom activities. Journal of Educational Psychology, 80, 514-523. 
Middleton, J. A., \& Spanias, P. A. (1999). Motivation for achievement in mathematics: Findings, generalizations, and criticisms of the research. Journal for Research in Mathematics Education, 30, 65-88. Retrieved from https:/www.jstor.org/stable/749630

Middleton, J. A., Tallman, M., Hatfield, N., \& Davis, O. (2015). Taking the severe out of perseverance: Strategies for building mathematical determination. In N. Alpert (Ed.), The Collected Papers. Chicago, IL: Spencer Foundation. Available Retrieved from http://www.spencer.org/collected-papers-april-2015

Mueller, C. M., \& Dweck, C. S. (1998). Praise for intelligence can undermine children's motivation and performance. Journal of Personality and Social Psychology, 75(1), 33-52.

Nicholls, J. G. (1984). Achievement motivation: Conceptions of ability, subjective experience, task choice, and performance. Psychological Review, 91(3), 328-346.

Pekrun, R. (2006). The control-value theory of achievement emotions: Assumptions, corollaries, and implications for educational research and practice. Educational Psychology Review, 18, 315-341. Retrieved from https:/link.springer.com/article/10.1007/s10648-006-9029-9

Peterson, C., \& Seligman, M. E. P. (2004). Character strengths and virtues: A handbook and classification. New York: Oxford University Press/ Washington, DC: American Psychological Association.

Pintrich, P. R. (1989). The dynamic interplay of student motivation and cognition in the college classroom. Advances in motivation and achievement, 6, 117-160.

Polya, G. (1957). How to solve it (2nd ed.). Garden City, NY: Doubleday Anchor Books.

Renninger, K. A., \& Bachrach, J. E. (2015). Studying triggers for interest and engagement using observational methods. Educational Psychologist, $\quad 50(1), \quad$ 58-69. https://doi.org/10.1080/00461520.2014.999920

Rickles, J. H. (2013). Examining heterogeneity in the effect of taking algebra in eighth grade. The Journal of Educational Research, 106, 251-268. https://doi.org/10.1080/00220671.2012.692731

Ryan, R. M., \& Deci, E. L. (2000). Intrinsic and extrinsic motivations: Classic definitions and new directions. Contemporary Educational Psychology 25, 54-67. https://doi.org/10.1006/ceps.1999.1020

Sansone, C., Wiebe, D. J., \& Morgan, C. (1999). Self-regulating interest: The moderating role of hardiness and conscientiousness. Journal of Personality, 67(4), 701-733. https://doi.org/10.1111/14676494.00070

Stanic, G., \& Kilpatrick, J. (1989). Historical perspectives on problem solving in the mathematics curriculum. In R. Charles \& E. Silver (Eds.), The teaching and assessing of mathematical problem solving (pp. 1-22). Reston, VA: National Council of Teachers of Mathematics.

Tulis, M., \& Fulmer, S. M. (2013). Students' motivational and emotional experiences and their relationship to persistence during academic challenge in mathematics and reading. Learning and Individual Differences, 27, 35-46. https://doi.org/10.1016/j.lindif.2013.06.003

Urdan, T., \& Mestas, M. (2006). The goals behind performance goals. Journal of Educational Psychology, 98(2), 354-365. http://psycnet.apa.org/doi/10.1037/0022-0663.98.2.354

Vollmeyer, R., \& Rheinberg, F. (2000). Does motivation affect performance via persistence? Learning and Instruction, 10, 293-309. https://doi.org/10.1016/S0959-4752(99)00031-6

Warshauer, H. K. (2014). Productive struggle in middle school mathematics classrooms. Journal of Mathematics Teacher Education, 18(4), 375-400. https://doi.org/10.1007\%2Fs10857-014-9286-3

Wrosch, C., Scheier, M. F., Miller, G. E., Schulz, R., \& Carver, C. S. (2003). Adaptive selfregulation of unattainable goals: Goal disengagement, goal reengagement, and subjective well-being. Personality and Social Psychology Bulletin, $\quad$ 29(12), https://doi.org/10.1177\%2F0146167203256921

Yeager, D. S., \& Walton, G. M. (2011). Social-psychological interventions in education: They're not magic. Review of Educational Research, 81(2), 267-301. https://doi.org/10.3102\%2F0034654311405999

Zimmerman, B. J. (1990). Self-regulated learning and academic achievement: An overview. Educational Psychologist, 25, 3-17. https://doi.org/10.1207/s15326985ep2501_2 